Article

\title{
Impact of Environmental Conditions on Grass Phenology in the Regional Climate Model COSMO-CLM
}

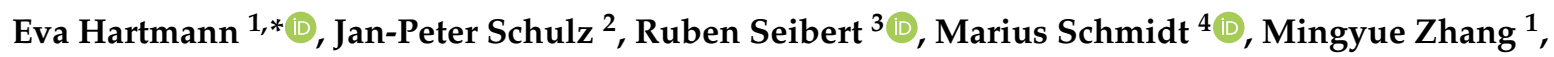
Jürg Luterbacher ${ }^{1,5,6}\left(\mathbb{D}\right.$ and Merja $H$. Tölle 1,7 $^{-}$

1 Department of Geography, Climatology, Climate Dynamics and Climate Change, Justus-Liebig University Giessen, D-35390 Giessen, Germany; Mingyue.Zhang@geogr.uni-giessen.de (M.Z.);

juerg.luterbacher@geogr.uni-giessen.de or jluterbacher@wmo.int (J.L.);

Merja.Toelle@geogr.uni-giessen.de (M.H.T.)

2 Deutscher Wetterdienst DWD (German Meteorological Service), D-63067 Offenbach, Germany; Jan-Peter.Schulz@dwd.de

3 Department of Biology, Plant Ecology, Justus-Liebig University Giessen, D-35390 Giessen, Germany; Ruben.Seibert@bot2.bio.uni-giessen.de

4 Institute of Bio- and Geosciences, Agrosphere (IBG-3), Forschungszentrum Jülich, D-52428 Jülich, Germany; ma.schmidt@fz-juelich.de

5 Science and Innovation Department, World Meteorological Organization (WMO), CH-1211 Geneva, Switzerland

6 Center of International Development and Environmental Research, Justus-Liebig University Giessen, D-35390 Giessen, Germany

7 Center of Environmental Systems Research (CESR), University of Kassel, D-34117 Kassel, Germany

* Correspondence: Eva.Hartmann@geogr.uni-giessen.de

Received: 13 November 2020; Accepted: 10 December 2020; Published: 16 December 2020

\begin{abstract}
Feedbacks of plant phenology to the regional climate system affect fluxes of energy, water, $\mathrm{CO} 2$, biogenic volatile organic compounds as well as canopy conductance, surface roughness length, and are influencing the seasonality of albedo. We performed simulations with the regional climate model COSMO-CLM (CCLM) at three locations in Germany covering the period 1999 to 2015 in order to study the sensitivity of grass phenology to different environmental conditions by implementing a new phenology module. We provide new evidence that the annually-recurring standard phenology of CCLM is improved by the new calculation of leaf area index (LAI) dependent upon surface temperature, day length, and water availability. Results with the new phenology implemented in the model show a significantly higher correlation with observations than simulations with the standard phenology. The interannual variability of LAI improves the representation of vegetation in years with extremely warm winter/spring (e.g., 2007) or extremely dry summer (e.g., 2003) and shows a more realistic growth period. The effect of the newly implemented phenology on atmospheric variables is small but tends to be positive. It should be used in future applications with an extension on more plant functional types.
\end{abstract}

Keywords: climate change; COSMO-CLM; land atmosphere interactions; leaf area index; phenology; regional climate model; vegetation modeling

\section{Introduction}

Phenology is the timing of seasonal activities of animals and plants [1,2]. It indicates changes in ecology [2] which are linked to local or regional climate variability [3]. Phenology is also affected by climate change [4,5], since the 1950s, the growing season in temperate Europe lengthened by 3.6 days 
per decade $[2,6,7]$. With higher $\mathrm{CO}_{2}$ concentrations and warmer conditions, the growing season will further extend [8].

The phenology mainly depends on the vegetation type, but also temperature and precipitation influence the phenological stages [9]. Additionally, the length of the photoperiod (day length) plays an important role, and together with temperature influences the length of the growing period $[10,11]$. The precipitation and the available soil water are important for the variability during the phenophase [12]. Years with an exceptional course of phenology are also associated with extreme temperature and/or precipitation [13]. When a year starts with an anomalous warm winter and spring, the vegetation usually also starts growing earlier, and later when winter and spring are cold. The end of the growing season is usually earlier when the late summer or autumn is colder than usual, and later when it is warm [14]. Precipitation as a source for soil water has a strong influence on the development of the leaf area index (LAI, the leaf area per unit area of land [15]) especially in summer during the growing season [16]. With precipitation, more water is available for the plants. In a year with less precipitation, there is less water available thus a reduction of the LAI is observed [17].

Inversely, the energy and water cycle of the regional climate is influenced by the phenological development of the vegetation through albedo, and sensible and latent heat flux changes [18]. This influences near-surface air temperature and boundary layer structure, and ultimately the precipitation. The impact of vegetation on the weather and climate conditions $[19,20]$ is most visible in extreme events as the 2003 European summer heatwaves [21]. The sensitivity of latent heat flux to vegetation is well understood. More vegetation leads to more latent heat flux resulting in more humidity in the boundary layer especially during summer and during daytime when radiation is highest $[18,22,23]$.

Phenology and associated vegetation dynamics are accounted for in many different land surface models and still need improvements [24]. Main examples are the Community-Land Model (CLM) [25], the Lund-Potsdam-Jena (LPJ) [26] and ORCHIDEE [27] models. These land surface models represent different interactions between the atmosphere and the vegetation including (amongst others) energy, water, and $\mathrm{CO}_{2}$ fluxes. In ORCHIDEE for example, in 2003 higher insolation in spring enhances evapotranspiration in June leading to land surface cooling, whereas in August the evapotranspiration is reduced by water stress leading to an early leave fall [21]. These sophisticated land surface models can be coupled to different regional climate models and global models. The computational costs of a model increase with complexity and resolution [28]. Therefore, those complex models often have a rather coarse horizontal resolution $(\sim 12-50 \mathrm{~km})$. High horizontal resolution $(\sim 1-3 \mathrm{~km})$ and less computational demand can be achieved through less complex models. For example, the regional climate model COSMO-CLM (CCLM) is used for applications at a convection-permitting scale with the land surface model TERRA-ML [29-31]. It is a land-surface model of the second generation with lower complexity [32]. In CCLM, the phenology is static and does not depend on the environmental conditions. It follows a sinusoidal cycle depending on the geographical latitude and altitude $[29,33]$. Because those are constants, the annual cycle is every year the same for each simulated location. The annual cycle of LAI starts with the growth of the vegetation in spring and ends with the senescence in autumn, every year on the same days. In reality, those events differ from year to year, therefore this should also be the case in the model. Vegetation-atmosphere interactions need to be accurately represented in regional climate models to improve projections. The static annually-recurring phenology is in contradiction to the changing phenological cycle due to climate change that is observed. The CCLM is neither able to simulate the interannual variability of vegetation nor the feedbacks between climate and vegetation. Therefore, the model needs to be improved through phenology susceptible to environmental conditions. Models calculating phenology based on temperature give better results compared to satellite observations than models with complex photosynthetic modules [34]. That is why a calculation of phenology based on temperature is chosen [35].

The main objective of this study is to implement a new phenology calculation for grassland in the CCLM model. The new phenology depends on the surface temperature, the day length, and the 
water availability, allowing for interannual variability of the LAI. We will examine three experimental areas in Germany from 1999 to 2015. The simulated mean annual cycle and the annual cycle of extreme years of LAI will be compared to observations which will be validated in the first step. Furthermore, the influence of phenology on the latent heat flux and extreme events of temperature and precipitation will be studied. To assess the performance of this new phenology, the following research questions will be addressed:

1. How is the annual cycle of LAI affected by the newly implemented phenology?

2. Do extreme climatic conditions have a changed impact with the new phenology module in CCLM?

3. What is the influence of the phenology on atmospheric variables, such as temperature, humidity, and precipitation, with special attention to extreme events?

\section{Materials and Methods}

\subsection{Meteorological Observations}

Figure 1 shows the three experimental sites which are used in this study. The Lindenberg Meteorological Observatory (station ID 03015) is operated by the German Meteorological Service (Deutscher Wetterdienst, DWD) [36] and temperature and precipitation data are freely available. The latent heat flux was measured as part of the Coordinated Enhanced Observing Period (CEOP [37]) project with an infrared hygrometer in $2.4 \mathrm{~m}$ height from 2003 to 2013. Meteorological measurements of temperature, precipitation, and latent heat flux for individual years (2009-2011) of the GiFACE project [38,39] are available for the measuring station of the University of Giessen at Linden. The experimental crop site of Selhausen is operated by the Institute of Bio- and Geosciences, Agrosphere (IBG-3) of the Forschungszentrum Jülich [40,41]. Measurements of air temperature and latent heat flux (2011-2018) from the site are available at the CRC/TR32 database or the TERENO data portal. In addition, precipitation data from the DWD station Jülich (02473) is included. The station data is used to find extremely warm/dry years.
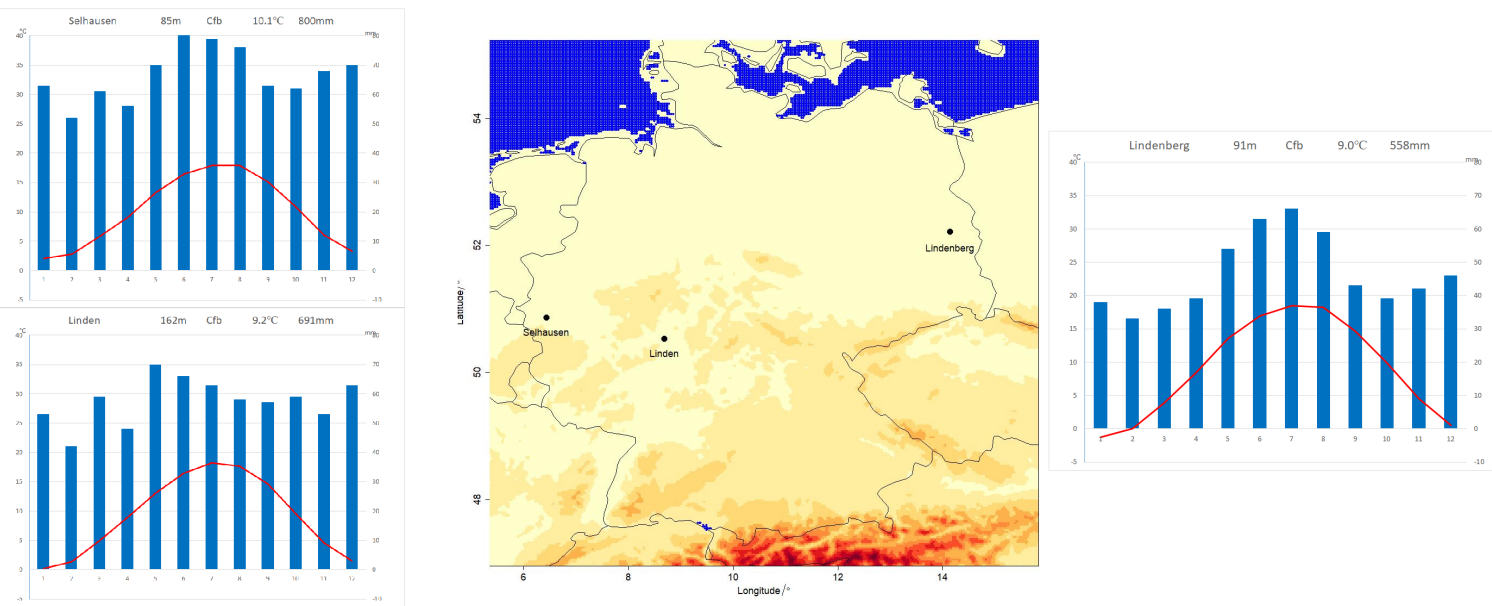

Figure 1. Map (center) with the three experimental locations (Lindenberg, Linden, and Selhausen) surrounded by their (Selhausen—topleft, Linden-bottomleft, Lindenberg—right) climate diagrams (data from Reference [42], 1982-2012), where the monthly precipitation sums are marked with blue bars and the annual cycle of monthly mean temperatures is shown in red.

Precipitation and temperature information is also taken from HYRAS (Hydrologische Rasterdatensätze-hydrological raster datasets) , a high-resolution gridded daily data set with $5 \mathrm{~km}$ spatial and a daily temporal resolution [43]. The HYRAS data set is calculated from the information of approximately 6200 stations including the DWD stations using the REGNIE (Regionalisierte Niederschlagshöhen-regionalized precipitation totals) method, a combination of multiple linear 
regression considering orographical conditions and inverse distance weighting [43]. This daily gridded data set is used to derive heavy precipitation and hot temperature events. The threshold for heavy precipitation amount at a certain time is set to $20 \mathrm{~mm}$ per day [44,45]. An extremely hot day is defined as a day within the 90 th percentile of maximum temperature $[46,47]$.

\subsection{LAI Measurements}

Indirect methods based on radiation measurements are applied to measure the LAI. The indirect method is not as precise as the direct method (collect leaves and measure their area) but can easily be automated and is less expensive and complex [48]. One of the common indirect methods is the plant canopy analyzer LAI-2000 [49] or the SunScan SS1 LAI meter (Delta-T Devices Ltd., Cambridge, UK). Here LAI is determined by measuring the light extinction in a canopy that is related to LAI. The indirect method is used at Linden and Selhausen to obtain the leaf area index. The measurements are made over grassland covering an area of about $100 \mathrm{~m} \times 200 \mathrm{~m}$ in Linden from 1998 to 2002 [50] and from 2014 to 2016 and in Selhausen from 2016 to 2018 over crops (2016: barley followed by greening mix, 2017: sugar beet, 2018: winter wheat).

We also use satellite observed leaf area index data because in-situ measurements are very sparse regarding spatial and temporal resolution. The LAI is calculated from the satellite product of SPOT and PROBA-V [51], derived from the normalized reflectance of red, near-infrared, and shortwave-infrared radiation [52]. Because the vegetation is not equally distributed in reality, it comes to an irregular distribution of the plants within remote sensing products (clumping). Therefore, this product uses a method to distribute the vegetation equally in the resolved grid [53]. The data is provided by the University of Hamburg with a horizontal resolution of $1 \mathrm{~km}$ and a temporal resolution of 10 days from 1999 to 2015 [54,55]. For comparison with the simulations, one grid cell of the gridded leaf area index is used at each experimental domain. One pixel of the satellite data is 50 times larger than the area of the in-situ measurements. This means that there is not only grass in this pixel but also other vegetation types including forests and crops and non-vegetated surfaces (urban areas). The LAI measurements from the FACE $[38,39]$ and the Tereno project $[40,41]$ are used to validate the satellite observations at the two specific areas because in-situ measurements of LAI have much more precise results at a specific location but cover a limited area and time. The satellite observations are finally used to evaluate the simulations at the three locations and for the whole period.

\subsection{COSMO-CLM}

The simulations are performed with the regional climate model COSMO-CLM [56]. COSMO-CLM is the model of the COnsortium for Small-scale MOdelling (COSMO) in CLimate Mode [56,57] and is the community model of the German regional climate research community jointly further developed by the CLM-Community. The COSMO model version 5.0 with CLM version 15 (COSMO-CLM v5.0_clm15) is used. The interpolation from the forcing ERA-Interim reanalysis data [58] to the model is done with INT2LM in version 2.05 with CLM version 1 (INT2LM - v2.05_clm1) [33]. The time-integration is the two time-level Runge-Kutta scheme [59] and the model time step is $25 \mathrm{~s}$. The shallow convection parameterization based on the Tiedtke scheme [60] is used. The land surface model is TERRA-ML [29,30]. It is a multi-layer scheme that computes temperature and water content on 10 soil layers. The bare soil evaporation and the transpiration by plants are simulated following the BATS scheme [32], together they form the evapotranspiration. The transpiration is based on a Jarvis-type [61] formulation depending on several environmental stress factors, taking into account the LAI. The external data set is prepared with EXTPAR [62] and the parameters for vegetation are adjusted to grassland, meaning the leaf area index (0.6-2.4), the root depth $(0.2 \mathrm{~m})$, and the vegetation area fraction (0.7-0.8). This allows for a pure sensitivity study including only the differences between the parameterizations of grass phenology. The simulations can be compared without being influenced by differences in land coverage. 
The simulations are carried out at three different locations in Germany. Those are Lindenberg $\left(\right.$ Lat $=52.220^{\circ}$, Lon $=14.135^{\circ}$, Alt $\left.=91 \mathrm{~m}\right)$ in Brandenburg, Linden $\left(\right.$ Lat $=50.531^{\circ}$, Lon $=8.704^{\circ}$, Alt $=162 \mathrm{~m})$ close to Giessen in Hesse and Selhausen $\left(\right.$ Lat $=50.855^{\circ}$, Lon $=6.439^{\circ}$, Alt $\left.=85 \mathrm{~m}\right)$ close to Jülich in North Rhine-Westphalia (Figure 1). At each location, simulations in a small domain of $25 \times 25$ grid points with a mesh size of $0.0275^{\circ}(\sim 3 \mathrm{~km})$ around a central grid point at the observational site are performed. This central grid point is cut out with all vertical layers to examine only the single column. Each domain is simulated from 1999 to 2015.

\subsection{Implementation of the Phenology Scheme}

A general logistic approach for an annually changing phenology is the LPJ philosophy of the Lund-Potsdam-Jena Dynamic Global Vegetation Model (LPJ-DGVM) [26,63] in the form

$$
\frac{d \Lambda}{d t}=r \Lambda\left(1-\frac{\Lambda}{\Lambda_{\max }}\right)-p \Lambda
$$

where LAI is $\Lambda$ and its maximum value is $\Lambda_{\max }$, the growth rate is $r$ and the shedding rate is $p$. It is used in the LPJ as well as in JSBACH $[64,65]$. The latter is the component for land and vegetation of the MPI Earth System Model [66]. The MPI regional climate model REMO-iMOVE [67,68], a new model version with dynamic vegetation phenology of REMO, also uses this approach. For our purposes, it has the disadvantage that it requires the availability of NPP in the model. But, since the COSMO atmospheric model does not include a carbon cycle we restrict ourselves to schemes without the need of NPP.

A simpler and more robust phenology model which fulfills this criterion is the one by Knorr et al. (2010) [35]. We adapt this model to CCLM for grassland based on the developments by Schulz et al. (2015) [69]. All parameters used in the following equations are described in Table 1 and min / $\max$ are minimum and maximum values. The equations published by Knorr et al. (2010) [35] in a general form are implemented in the source code of CCLM as a new module step-by-step starting with the dependence on temperature, followed by the dependence on day length, and followed by the dependence on water availability. Therefore, the equations by Knorr et al. (2010) [35] are adapted to the use in CCLM using the approach by Schulz et al. (2015) [69] and extending it to the complex model structure of CCLM. Schulz et al. (2015) [69] implemented the equations by Knorr et al. (2010) [35] in an offline version of TERRA including only the dependence on temperature. The new module is called prior to the land surface model TERRA-ML during the model run of CCLM. In this way, the transpiration and all other influenced parameters are calculated with the new LAI.

Table 1. Parameters of the newly implemented phenology model based on Knorr et al. (2010) [35].

\begin{tabular}{lll}
\hline Symbol & Description & Units \\
\hline$\Lambda$ & leaf area index & - \\
$t, \Delta t$ & time, time step & $\mathrm{s}$ \\
$r, p$ & growth rate, shedding rate & days $^{-1}$ \\
$T_{S}$ & soil surface temperature & ${ }^{\circ} \mathrm{C}$ \\
$\tau_{m}$ & averaging time for temperature & $\mathrm{s}$ \\
$T, T_{o n}$ & phenology temperature, threshold & ${ }^{\circ} \mathrm{C}$ \\
$\Lambda_{T}$ & LAI depending on temperature (and day length) & - \\
$\varphi$ & latitude & rad \\
$\delta$ & declination of the sun & rad \\
$t_{d}, t_{o n}$ & day length, threshold & $\mathrm{h}$ (hours) \\
$W_{c}, W_{\max }$ & water content, maximum available & $\mathrm{m}$ \\
$\tau_{S}$ & averaging time for water availability & $\mathrm{s}$ \\
$\Lambda_{W}$ & LAI with water dependence & - \\
$\Lambda_{S}$ & LAI with smoothed water availability & - \\
\hline
\end{tabular}




\subsubsection{Dependence on Temperature}

The first step is to implement the phenology depending exclusively on the temperature. The air and surface temperature can change very fast but the vegetation needs its time to react. Therefore, a phenology determining temperature $T$ is introduced [35]. It is defined as a temperature $T$ depending on the soil surface temperature $T_{S}$ at the former time step, weighted exponentially [35]:

$$
T(t+\Delta t)=T(t) \cdot e^{-\Delta t / \tau_{m}}+T_{S}(t) \cdot\left(1-e^{-\Delta t / \tau_{m}}\right) .
$$

Following the work by Schulz et al. (2015) [69] the averaging period for the surface temperature is chosen to be $\tau_{m}=15$ days. Now the leaf area index $\Lambda_{T}$ depending on the temperature can be calculated as follows:

$$
\Lambda_{T}(t+\Delta t)=\left\{\begin{array}{ll}
\Lambda_{\max }-e^{-r \Delta t} \cdot\left(\Lambda_{\max }-\Lambda_{T}(t)\right), & \text { if } T \geq T_{\text {on }} \\
\Lambda_{\min }-e^{-p \Delta t} \cdot\left(\Lambda_{\min }-\Lambda_{T}(t)\right), & \text { else }
\end{array},\right.
$$

where the growth rate is chosen to be $r=0.07$ days $^{-1}$ which is an empirically tuned value and the shedding rate is the same $p=r$ [69]. The results of simulations with this implementation are in the following denoted as ${ }^{\prime} \_T^{\prime}$. The threshold of the temperature is commonly set to 0 or $5^{\circ} \mathrm{C}$ [70]. Following again Schulz et al. (2015) [69] it is set to $T_{o n}=5^{\circ} \mathrm{C}$.

\subsubsection{Dependence on Day Length}

The day length at a specific location contributes to the timing of vegetation growth and decay. The day length depends on the latitude $\varphi$ and the declination $\delta$ of the sun. It is calculated as

$$
t_{d}=\arccos (-\tan \varphi \cdot \tan \delta) \cdot 24 \mathrm{~h} / \pi,
$$

and is given in hours. Now the leaf area index $\Lambda_{T}$ depending on the temperature and the day length calculates as

$$
\Lambda_{T}(t+\Delta t)= \begin{cases}\Lambda_{\max }-e^{-r \Delta t} \cdot\left(\Lambda_{\max }-\Lambda_{T}(t)\right), & \text { if } T \geq T_{\text {on }} \text { and } t_{d} \geq t_{\text {on }} \\ \Lambda_{\min }-e^{-p \Delta t} \cdot\left(\Lambda_{\min }-\Lambda_{T}(t)\right), & \text { else }\end{cases}
$$

To have a Central European growing period which lasts at the most from February to October the threshold for the day length is set to $t_{o n}=10 \mathrm{~h}$. The results of simulations with this implementation are denoted as ${ }^{\prime} T D^{\prime}$.

\subsubsection{Dependence on Water Availability}

The water available for the plant is mainly determined by the water content of the soil. It influences the transpiration by plants [71]. The water availability is even more important for plant growth than the temperature [72]. Therefore, water availability has to affect the LAI in the model appropriately. The water availability is adapted from the approach by Knorr et al. (2010) [35] to the CCLM.

The water available for the plants is the soil water that can be reached with the roots. This is calculated in the model using all soil layers within the root depth of the vegetation and is called water content $W_{c}$. The maximum for the plant available water content $W_{\max }$ is also needed to obtain the ratio of available to maximum water content. It can be calculated as the difference between the field capacity $F C A P$ and the permanent wilting point $P W P$. With the help of these variables a water-dependent leaf area index $\Lambda_{W}$ is calculated with

$$
\Lambda_{W}=\Lambda_{T} \cdot \frac{W_{c}}{W_{\max }} .
$$

This is implemented in the model through a smoothed minimum function [35]: 


$$
\Lambda_{S}=\frac{\Lambda_{T}+\Lambda_{W}-\sqrt{\left(\Lambda_{T}+\Lambda_{W}\right)^{2}-4 \eta \Lambda_{T} \Lambda_{W}}}{2 \eta},
$$

where $\Lambda_{S}$ is the smoothed water available leaf area index and $\eta=0.99$. Finally, these steps are combined with the equation of the dependence on temperature and day length. The following equation gives the complete formulation of the leaf area index $\Lambda$ depending on the temperature, the day length, and the water availability:

$$
\Lambda(t+\Delta t)=\Lambda_{T} \cdot e^{-\Delta t / \tau_{s}}+\Lambda_{S} \cdot\left(1-e^{-\Delta t / \tau_{s}}\right)
$$

Results of simulations with all parts of the new phenology implemented are denoted as ${ }_{-} T D W^{\prime}$.

\section{Results and Discussion}

\subsection{Validation of LAI Observations}

The availability of in-situ measurements of the LAI at the stations Linden and Selhausen is very special because those measurements are very limited. They can be used to validate the satellite data with less precise results at a specific location but constant horizontal and temporal resolution over a large domain and period (Figure 2). The in-situ measurements of LAI at Linden have two peaks per year because the grass is cut twice a year. The first cutting is between the end of May and the beginning of June showing the first decrease of LAI. The second cut is in September associated with the second decrease of LAI. The satellite observation in the pixel including Linden shows the first peak of LAI and a slightly increased value during the second peak of the in-situ measurements. At Selhausen, the crops are harvested at a different time but only once each year, hence the differences in the in-situ measurements of LAI in Figure 2. In the satellite observation over Selhausen, the first peak is nearly at the same time as over Linden. It can also be seen in the in-situ measurements (2016: barley, 2018: winter wheat). The second peak is also pronounced in the satellite observations but still with an only slightly increased signal. At the same time, the peak appears in the in-situ measurements of 2017 (sugar beet) and later in 2016 (greening mix). Those differences between the observations should be kept in mind when evaluating the model results in the following sections.
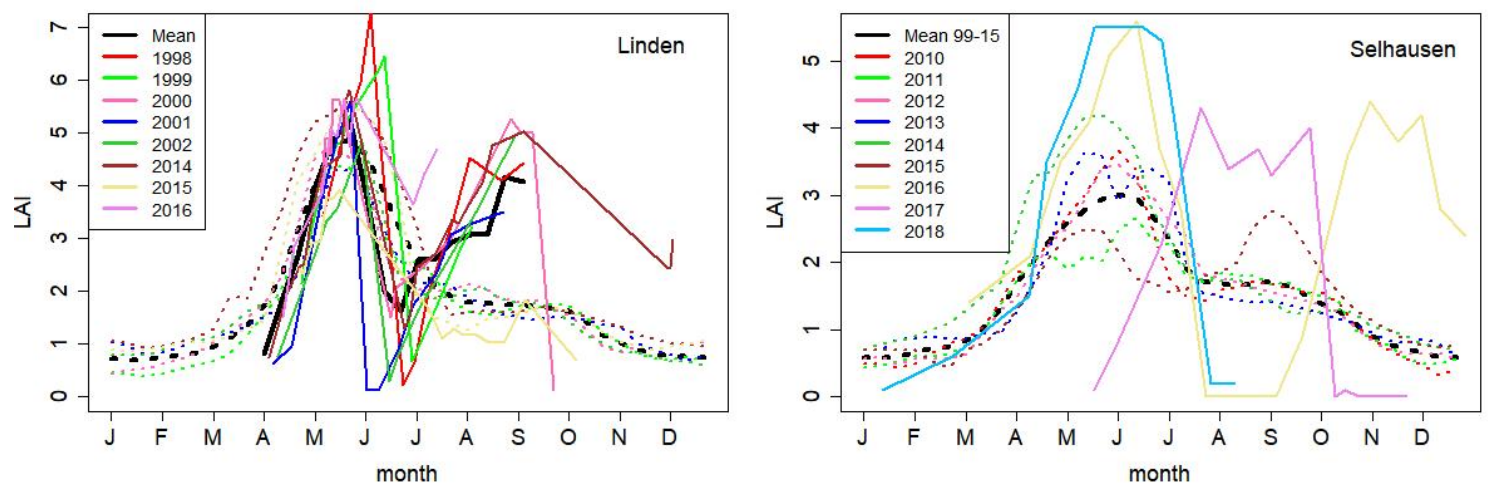

Figure 2. Leaf area index (LAI) satellite (dotted) and in-situ (solid lines) observations at Linden and Selhausen for the years shown in the legend on the left in different colors. In-situ measurements are only available for the given years and dates. At Linden, the shown simulated years are (except 1998) the same as the in-situ observations. At Selhausen, the six years of simulations before the in-situ observations are shown. The mean annual cycle of the satellite LAI for the given years is shown in black (-). 


\subsection{Annual Cycle of LAI}

The mean annual cycle of LAI from 1999 to 2015 is shown in Figure 3 for the three experimental domains. The timing of the maximum LAI in the simulations is closest to observations with the newly implemented phenology. The maximum value of LAI of the standard simulations is reached in July whereas in the observations it is between May and June. Implementing the temperature dependence, the LAI stays at maximum from June to November. Implementing additionally the dependence on day length, it follows the same mean annual cycle as with only the dependence on temperature except for the earlier decrease in September. At the end of the growing season, the day length threshold intervenes earlier than the temperature threshold. The water availability of the complete newly implemented phenology reduces the LAI in summer which is why the maximum value is between May and June, the same time of the year as in the observations. Also, the start of the growing season of the simulations with the newly implemented phenology is in very good agreement with the observations. This applies to all simulations except for those with the standard phenology. More details will follow in the next section. However, the decrease of LAI starts later and faster in the simulations compared to the observations but it ends at a similar time (except for the simulation only depending on temperature).
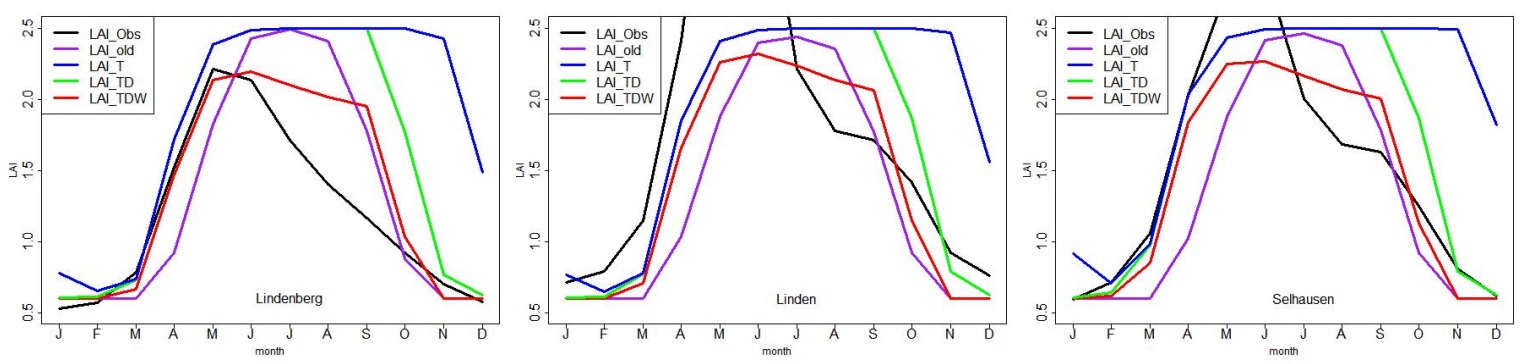

Figure 3. Mean (1999-2015) annual cycle of LAI. Results with the standard phenology(_old,-),

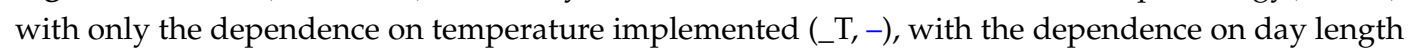
added (_TD, - ), with the fully implemented new phenology (_TDW, -), and satellite observations (_Obs,, ) are shown at the three experimental domains Lindenberg, Linden, and Selhausen.

Correlation coefficients $r$ between simulations and the observations are calculated to evaluate the quality of the different simulations (Table 2, statistical methods in the Appendix A.1). Very high and significant correlations are found for all simulations at the three stations. The highest correlation coefficients are found between the simulations with the new phenology and the satellite observations, followed by the simulations with the dependence on temperature and day length of the new phenology, the standard phenology, and finally, the phenology only depending on the temperature.

The improvement of the simulations compared to observations is quantified by Fisher's $z$ (statistical methods in the Appendix A.2). The values and their probabilities for the comparison of the new phenology to the old phenology are also shown in Table2. The improvement of the simulations from the standard to the new phenology is significant at all locations.

Table 2. Pearson's correlation coefficient $r$ for the monthly LAI of the different simulations from 1999 to 2015 compared to satellite observations (significant in bold), Fisher's $z$ for Pearson's $r$ of the standard simulation compared to the new phenology, and the $p$-value calculated from Fisher's $z$ (significant in bold).

\begin{tabular}{lcccccc}
\hline & $\begin{array}{c}r \text { (LAI_ } \\
\text { old } \sim \text { Obs) }\end{array}$ & $\begin{array}{c}r \text { (LAI_ } \\
\text { T } \sim \text { Obs) }\end{array}$ & $\begin{array}{c}r \text { (LAI_ } \\
\text { TD OObs) }\end{array}$ & $\begin{array}{c}r \text { (LAI_ } \\
\text { TDW } \sim \text { Obs })\end{array}$ & $\begin{array}{c}z \\
\text { (old } \sim \text { TDW) }\end{array}$ & $\begin{array}{c}p \text { (Fisher) } \\
(\text { old } \sim \text { TDW) }\end{array}$ \\
\hline Lindenberg & $\mathbf{0 . 7 3}$ & $\mathbf{0 . 5 6}$ & $\mathbf{0 . 7 7}$ & $\mathbf{0 . 8 2}$ & -2.287 & $\mathbf{0 . 0 1 1}$ \\
\hline Linden & $\mathbf{0 . 6 7}$ & $\mathbf{0 . 5 1}$ & $\mathbf{0 . 7 1}$ & $\mathbf{0 . 7 7}$ & -2.101 & $\mathbf{0 . 0 1 8}$ \\
\hline Selhausen & $\mathbf{0 . 7 6}$ & $\mathbf{0 . 5 7}$ & $\mathbf{0 . 8 1}$ & $\mathbf{0 . 8 6}$ & -2.979 & $\mathbf{0 . 0 0 1}$ \\
\hline
\end{tabular}


In summary, the mean annual satellite-observed cycle of LAI is represented most accurately in the model with the newly implemented phenology. In the following section, we analyze the start of the growing season (SGS) of each year.

\subsubsection{Start of the Growing Season}

The start of the growing season (SGS) is defined as the day when the LAI has reached $20 \%$ of its maximum value [34,73]. In Figure 4 the SGS is shown for the three domains in the satellite observations, the simulations with the standard phenology, and the simulations with the new phenology. In the simulations with the standard phenology, the SGS is constant because of the annually-recurring cycle. The observations as well as the new simulations, have a large interannual variability and are significantly positive correlated (Lindenberg $r=0.27$, Linden $r=0.64$, Selhausen $r=0.45$ ). For the majority of the years, the SGS of the simulations with the standard phenology is approximately 2 months later compared to the observations and the simulations with the new phenology (Figure 4). This is because the phenology in the standard simulation only depends on the latitude and altitude specifying the SGS at that date. When depending on temperature and day length in the new phenology module, the SGS is earlier in spring and therefore closer to the observations.
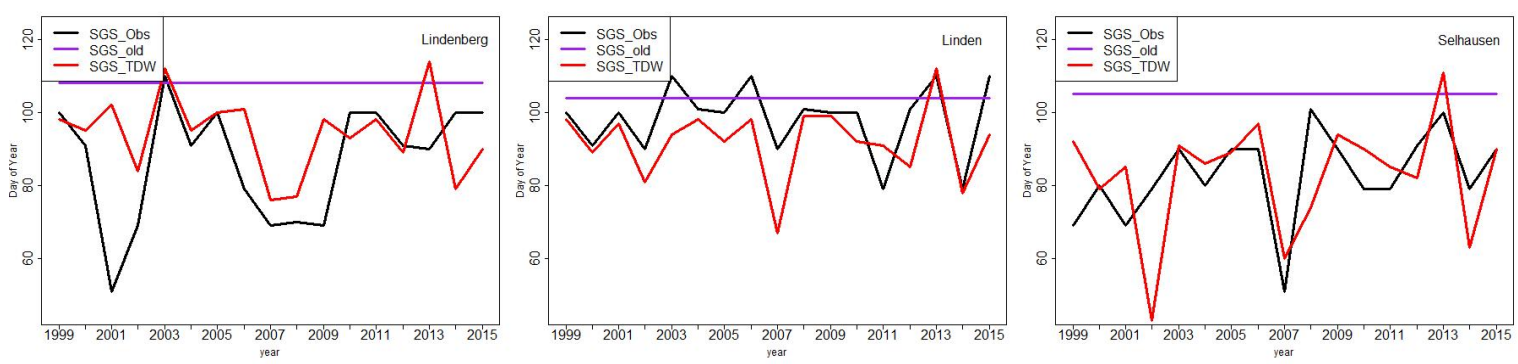

Figure 4. Start of the growing season (SGS) in number of days for each year from 1999 to 2015 and each domain (Lindenberg, Linden, and Selhausen) for satellite observations (_Obs, -), the standard phenology simulations (_old, -), and the new phenology simulations (_TDW, -).

In summary, the simulations with the newly implemented phenology with the interannual variability of SGS show a good similarity with the observations from satellite data. In the next section, this is studied more in detail for years with exceptionally warm winters/springs and exceptionally dry summers.

\subsubsection{Influence of Temperature and Precipitation Extremes}

Temperature and Precipitation are influencing the annual cycle of the LAI. The drier the summer is the more the LAI is reduced due to limited water availability. One of the driest summers at all locations occurred in 2003. The warmest winter and spring occurred in 2007 at Lindenberg, Linden and Selhausen. The most extreme years are found with the standardized temperature and precipitation at the different locations (not shown, method in the Appendix A.3).

For the years with extreme events, the annual cycle of LAI is presented in Figure 5. The satellite observations show a very sharp decrease in LAI during summer at all locations in 2003 and low maximum values at Lindenberg and Selhausen (upper panel of Figure5). With the simulations including the dependence on water availability in red, the decrease of LAI starts at the same time as in the observations but is not as steep. Especially in Selhausen the observations and the simulations with the newly implemented phenology are very close in 2003. 

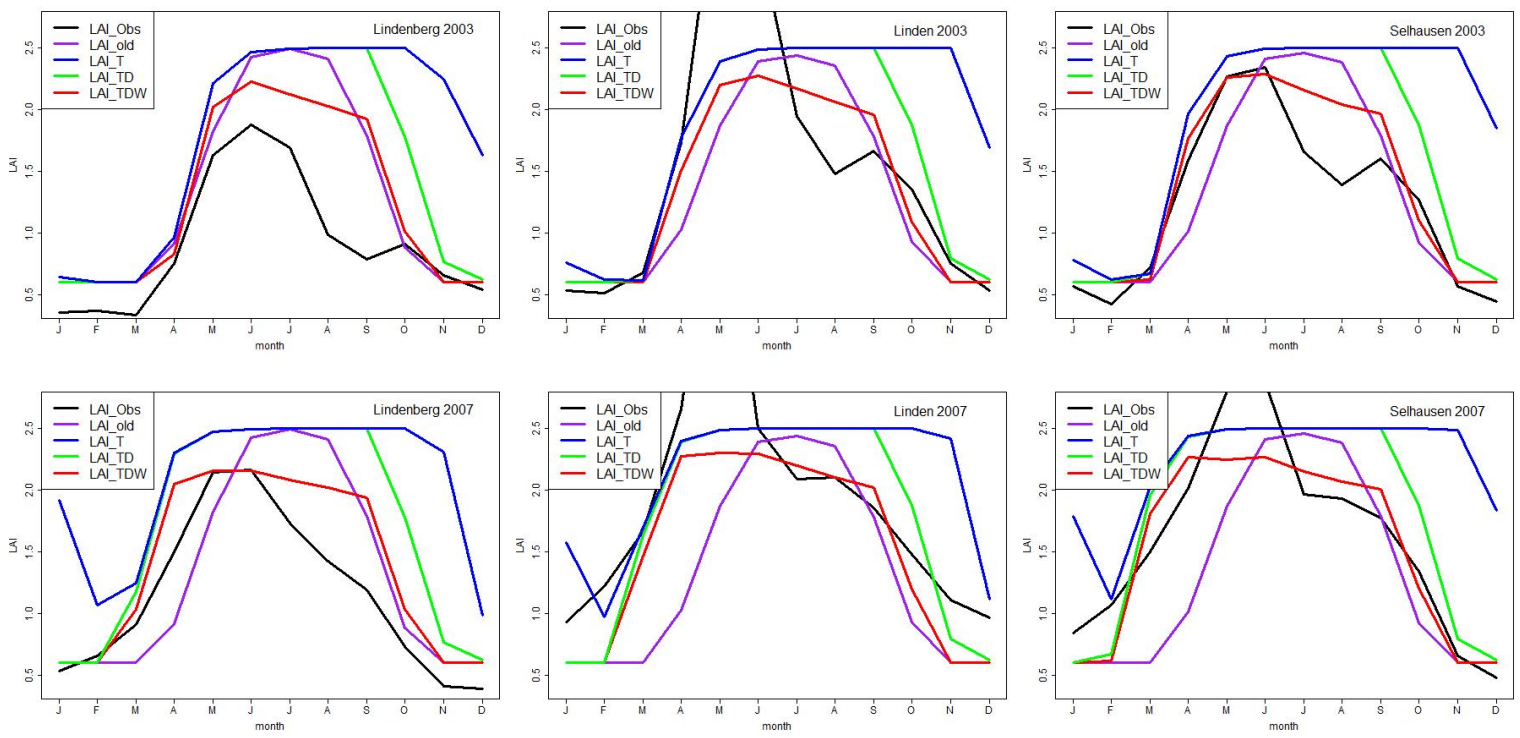

Figure 5. Annual cycle of LAI of the year 2003 with extremely dry summer (top) and the year 2007 with extremely warm spring (bottom) at Lindenberg (left), Linden (middle), and Selhausen (right). In black (-) are the satellite observations (_Obs) and in different colors the simulations with the standard phenology (_old, -$)$, with only the dependence on temperature $\left(\_T,-\right)$, the dependence on temperature and day length (_TD, -$)$, and with the new phenology (_TDW, - ).

The improvement in the annual cycle of LAI of the extreme year 2007 is shown in the lower panel of Figure 5. The early SGS shown in the satellite observations can be simulated with the newly implemented phenology because all simulations (_T, _TD,_TDW) show a clear temperature dependence. The standard phenology only depends on the latitude and the altitude thus does not have any variation also not in extreme years. Hence, the SGS in those years is about two months later (Figures 4 and 5). Especially in Lindenberg the simulation with the newly implemented phenology shows a high level of agreement with the observations.

In summary, we show that extreme temperature and precipitation events are influencing the annual cycle of LAI. In contrast to simulations with the standard phenology module, CCLM can reproduce interannual variations in the annual cycle of the LAI with the newly implemented phenology depending on surface temperature, day length, and water availability.

\subsection{Impacts of LAI on the Atmosphere}

\subsubsection{Impact on Latent Heat Flux}

Vegetation influences weather and climate mainly through transpiration. This can be measured by latent heat flux. The greatest differences between the mean annual LAI cycles of the simulations with the standard phenology and with the newly implemented phenology can be observed in March and in July (Figure 3). Those differences result from the dependence on temperature in March and from the dependence on water availability in July. Therefore, it is in particular interesting to look at the impacts on latent heat flux in the most extreme years 2007 (spring) and 2003 (summer). Observations of latent heat flux for those years are only available at Lindenberg and are shown in Figure 6. 

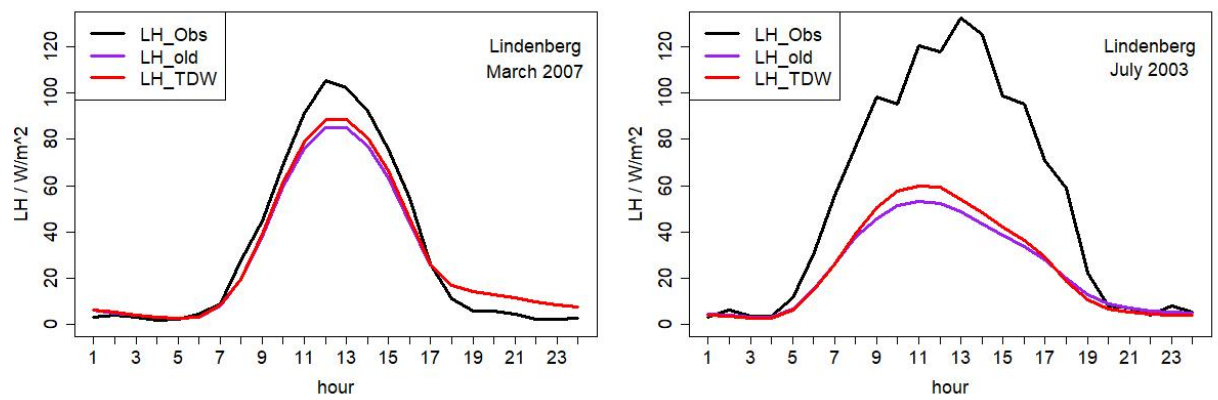

Figure 6. Mean diurnal cycle of latent heat flux during March 2007 and during July 2003 at Lindenberg for the simulations with the standard phenology (_old, -), the simulations with the new phenology (_TDW, -) and the observations (_Obs,,- ).

Figure 6 shows the mean diurnal cycle of latent heat flux for March 2007 and July 2003 at Lindenberg. During both months the observations have higher values than the simulations whereas the difference is much higher in July 2003. The difference between the simulations with the standard phenology and the newly implemented phenology is not significant but the latent heat flux simulated with the newly implemented phenology is closer at the observations in both cases. The same can be applied for example for March and July 2011 at Linden and for March and July 2013 at Selhausen (not shown).

In summary, the influence of the phenology on the simulated energy and water fluxes shown by the latent heat flux is small. But when the differences between the standard and the newly implemented phenology are highest, the simulations with the new phenology tend to show better results. This also influences the representation of all related variables like humidity and temperature as shown in the next section.

\subsubsection{Impact on Precipitation and Temperature Extremes}

The influence of phenology on extreme precipitation and temperature is shown in Figure 7. The simulations with the standard phenology and the new phenology are compared to the HYRAS gridded observational data set [43]. Heavy precipitation events with more than $20 \mathrm{~mm}$ precipitation on one day are shown in the upper panel of Figure 7. The number of heavy precipitation events is similar for all simulations and the observations at Lindenberg and Selhausen. At Linden, the simulations have, on average, twice as much heavy precipitation events as the observations. This could be due to the differences in land cover type between reality and the modified grassland in the simulations. The total number of heavy precipitation events in the simulations with the new phenology is closer to the observations in more years than with the standard phenology at Lindenberg and Linden and equal at Selhausen. But in general, the differences are small and not significant.

The number of days within the 90 th percentile of the maximum temperatures per year can be seen in the bottom part of Figure 7. The years with the most extreme warm days are the same in the simulations and the observations. The correlation coefficients $r$ between the simulations and the observations are with 0.89 for Lindenberg up to 0.99 for Linden very high. For Lindenberg, the average total number of days in the simulations is twice as much as in the observations, again this may be due to the differences in land cover type between the reality and the simulations. The average number of days with the new phenology tends to be closer to the observations than the number in the simulations with the old phenology. The number of years, where the number of extremely warm days fits better to the observations at Selhausen, is higher in the simulations with the new phenology (Figure 7). But again the differences are small and not significant. 

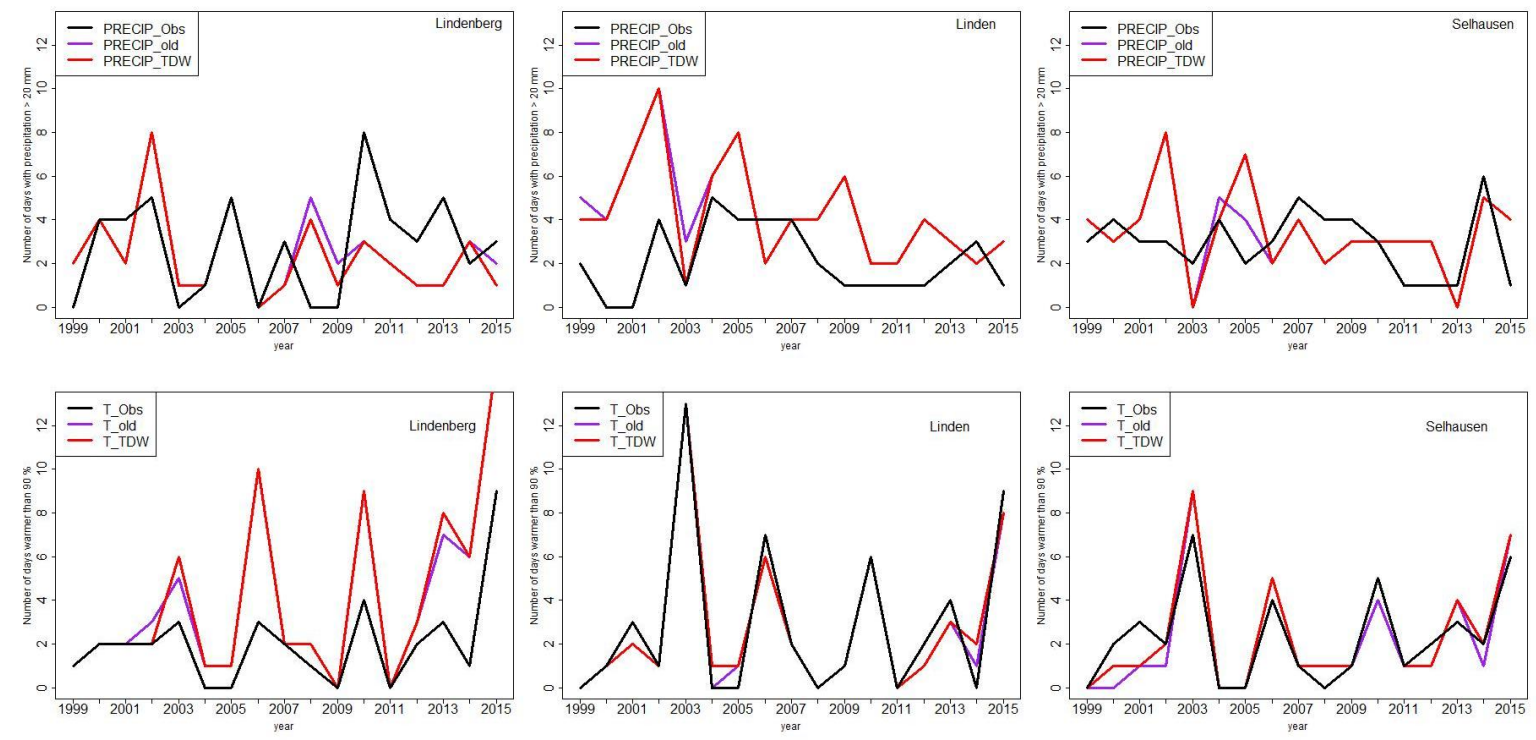

Figure 7. Heavy precipitation events with more than $20 \mathrm{~mm}$ per day (top) and very warm days within the 90 th Percentile of the observed maximum temperatures (bottom) in each year of the period 1999 to 2015 at Lindenberg, Linden and Selhausen for the HYRAS observations (_Obs, -), the simulations with the standard phenology (_old, - ) and the simulations with the new phenology (_TDW, - ).

In summary, the differences between the simulations with the new and the standard phenology regarding extreme events in precipitation and temperature are small and do only appear in several years.

\section{Discussion}

To evaluate the results of CCLM simulations with different parameterizations of phenology, they are compared to observations. The locations are chosen because of the availability of rare data like in-situ measurements of LAI and latent heat flux. This advantage is used in the first step to validate the remote sensing product for LAI. The major peak of the mean satellite observed LAI (Figure 2) is in very good agreement with the first peak of grass or the winter crops (e.g., barley, winter wheat) and the minor peak is in good agreement with the second growth of grass or the summer crops (e.g., sugar beet). That indicates a high percentage of human activities in the pixel of the satellite observations (cutting of grass and harvesting) (Figure 2). This is again in good agreement with the fact that in Germany, the part of human used land (agricultural, settlement, and transport area) is more than 65\% [74]. Similar values can be adapted to the three locations where the landscape of the surrounding areas is dominated by agriculture and settlement.

The same explanation can be applied when comparing the mean annual cycle of LAI, where two differences remain between the simulations with the new phenology and the observations (Figure 3). The first difference can be found with LAI values from July to October up to $1 \mathrm{~m}^{2} / \mathrm{m}^{2}$ higher in the simulations than in the observations. An explanation is the human impact through land use management. Humans cut grass and harvest crops during summer and early autumn. This is the period of the largest difference between the simulations and the observations in Figure 3. The human activities reduce the LAI in the observations, but this cannot be simulated in CCLM because it is not a natural process. Those processes can not be represented even in sophisticated models [75]. The second difference between the observations and the simulations is the maximum value of LAI. It is higher in the observations of Linden and Selhausen than in the simulations. This is because the maximum value of LAI is fixed in the model through the external parameters of grassland values. Those parameters could be questioned in future studies. Another reason is that the satellite observations of each grid 
point are related to different land-use classes like urban areas, agriculturally used areas, and grassland, whereas in the simulations all land-use classes are adjusted to grassland.

Even though the apparent human influence on the phenology of reality can not be shown, the representation of LAI in the model improved significantly compared to the standard phenology at all locations. The influence of human activities on phenology can be very different as can be seen in Figure 2 what makes it unpredictable. Therefore the model's independence on them is positively evaluated in summary. The general improvement could have been expected from the experience with an improved phenology in other models, like the regional climate model REMO [67,68], but here we achieved a substantial improvement for CCLM with a less complex approach. The same applies to the SGS which naturally improved by the variations due to dependence on temperature and day length.

In years with extreme climate conditions as an exceptionally warm winter and spring or exceptionally dry summer, the differences between the standard phenology and the newly implemented phenology are particularly obvious. The reduction due to water stress in the exceptionally dry summer 2003 [76] is improved compared to the simulations without dependence on water availability but is still limited by the thresholds given for grassland and still shows differences between observations and the model due to human impact. The winter and spring of 2007 were exceptionally warm with a strong impact on Germany's phenology [77]. The early onset of vegetation in this year can be seen with the newly implemented phenology leading to a notable improvement compared to the standard phenology.

The expected influence of vegetation on latent heat flux $[18,22]$ is shown in the simulations with the new phenology module. In years with exceptionally warm spring (2007) the latent heat flux is increased because the LAI is also higher compared to the standard phenology. The latent heat flux in years with exceptionally dry summer (2003) is also increased compared to the standard phenology. This can not be explained with the lower LAI but may be due to the additional lower fraction of plant coverage. The combination of those reductions results in lower transpiration. Lower transpiration earlier in the year means more available soil water is left in later summer. This allows for higher latent heat in July even in extremely dry years. Even though the impact of phenology on the latent heat flux is limited and the differences between simulations with the standard and the new phenology are not significant, especially the representation of extreme events tends to be improved.

The influence of phenology on extreme temperature (90th percentile of maximum temperature) and extreme precipitation ( $20 \mathrm{~mm}$ per day) is not significant. The differences between the simulations with the standard and with the new phenology are small and do only show up in individual years. The correlation between the simulated and the observed extreme temperature events is very high and did not change with phenology. The extreme precipitation events could not be improved but did also not impair. The influence of the phenology on extreme events seems not to be relevant at least on such small dimensions.

\section{Conclusions}

In this study, a new implementation of phenology in the COSMO-CLM model is presented. The LAI as an indicator for phenology is calculated in the new module depending on surface temperature, day length, and water availability. Simulations are performed at three locations in Germany (Lindenberg, Linden, and Selhausen) from 1999 to 2015 with the standard phenology, with phenology depending on temperature, depending on temperature and day length and with the complete new phenology. The results of the simulations with different calculation methods of LAI were compared with each other and with observations. The questions in the introduction can be answered as follows:

1. How is the annual cycle of LAI affected by the newly implemented phenology?

The representation of the annual cycle of LAI significantly improved using the newly implemented phenology compared to the standard phenology in CCLM. The timing of LAI 
including its increase, maximum, and decrease is closer to observations with the new simulations. The interannual variability of the simulated SGS is more consistent with the observations.

2. Do extreme climatic conditions have a changed impact with the new phenology module in CCLM? Extreme warm/dry years and their influence on phenology can be better resolved with the new phenology in CCLM. The previously static annual cycle of LAI is adjusted with the dependence on temperature and water availability to extreme environmental conditions. This also changes the atmospheric variables influenced by vegetation.

3. What is the influence of the phenology on atmospheric variables, such as temperature, humidity, and precipitation, with special attention to extreme events?

The newly implemented phenology causes changes in the energy and water cycle of the model compared to the standard simulations. An enhanced LAI in warm springs leads to more latent heat flux but also dry summers have enhanced latent heat in later summer because of fewer LAI combined with a fewer fraction of plant cover safes water earlier in the year in the soil which causes more transpiration later in the summer. The model with the standard phenology does not show the interannual differences and therefore misses this effect. The impact of phenology on extreme events of temperature and precipitation is too small to detect a significant improvement or deterioration with the new module.

The additional computational costs of the new phenology module are negligible and it can be implemented easily. Considering this and the significant improvement it achieves, the new phenology module will constitute a significant advance for CCLM. The newly implemented phenology has interannual variability, which reveals changes in vegetation due to climate change. The opposite effect of changes in phenology on climate change can also be seen. Both processes are very important for predicting future climate change with CCLM.

In summary, the newly implemented module for phenology is worth to be considered as a standard methodology to calculate the seasonal development of vegetation in CCLM. The representation of the biosphere in the model can be improved and the atmospheric and hydrological variables are at least not worsened. On a larger scale and also having the phenology of different plant functional types included, the improvements should be even more evident and also showing a noticeable effect on the atmosphere. This hypothesis should be tested in future work by extending the method presented here to other plant functional types and simulating it on larger areas.

Author Contributions: Conceptualization, E.H., J.-P.S. and M.H.T.; methodology, E.H., J.-P.S., J.L. and M.H.T.; software, E.H., J.-P.S., M.H.T.; validation, E.H. and M.Z.; formal analysis, E.H.; investigation, E.H. and M.Z.; resources, J.-P.S., R.S., M.S. and M.H.T.; data curation, E.H., R.S., M.S. and M.Z.; writing-original draft preparation, E.H.; writing-review and editing, J.-P.S., M.S., M.H.T. and J.L.; visualization, E.H.; supervision, J.L.; project administration, E.H. All authors have read and agreed to the published version of the manuscript.

Funding: This research was funded by the Justus Liebig University of Giessen and the German Research Foundation (DFG) through grant number 401857120. Computational resources were made available by the German Climate Computing Center (DKRZ) through support from the Federal Ministry of Education and Research in Germany (BMBF).

Acknowledgments: The authors acknowledge the German Meteorological Service (DWD) for providing observational data at the DWD Climate Data Center (CDC) and the HYRAS data. The SPOT/PROBA-V LAI data product was generated by the land service of Copernicus, the Earth Observation programme of the European Commission. The research leading to the current version of the LAI product has received funding from various European Commission Research and Technical Development programmes. The product is based on SPOT/VGT $1 \mathrm{~km}$ data ((c) CNES / PROBA-V $1 \mathrm{~km}$ data ((c) ESA and distributed by VITO), last access date: 28/9/2018. We acknowledge the GiFACE project at Linden for producing the LAI and meteorological data at the Justus-Liebig-University Gießen. We would like to thank the IBG-3 of the Forschungszentrum Jülich for providing us with measurement data collected in the framework of the Transregional Collaborative Research Center 32 (DFG) and the HGF initiative TERestrial ENvironmental Observations (TERENO).

Conflicts of Interest: The authors declare no conflict of interest. The funders had no role in the design of the study; in the collection, analyses, or interpretation of data; in the writing of the manuscript, or in the decision to publish the results. 


\section{Abbreviations}

The following abbreviations are used in this manuscript:

MDPI Multidisciplinary Digital Publishing Institute

CCLM COSMO-CLM

DWD German Meteorological Service (Deutscher Wetterdienst)

HYRAS hydrological raster datasets (Hydrologische Rasterdatensätze)

LAI Leaf Area Index

REGNIE regionalized precipitation totals (Regionalisierte Niederschlagshöhen)

SGS Start of Growing Season

\section{Appendix A. Statistical Methods}

Appendix A.1. Pearson Correlation

The Pearson correlation coefficient or Pearson's $r$ is used to measure the correlation between two variables $x$ and $y$ [78]. It has values between +1 and -1 with $r=1$ means total positive linear correlation, $r=0$ means no linear correlation, and $r=-1$ means total negative linear correlation. Pearson's $r$ is calculated with

$$
r=\frac{\operatorname{cov}(x, y)}{\sigma_{x} \sigma_{y}}
$$

cov is the covariance of the two respective variables and $\sigma_{x}$ and $\sigma_{y}$ are the standard deviations. When comparing simulation results to observations the correlation is best the closer $r$ is to 1 .

\section{Appendix A.2. Fisher Transformation}

The Fisher transformation is used to compare two different pearson correlation coefficients [79]. With calculating $z$ the relation of the different $r$ values can be estimated as follows

$$
z=\frac{1}{2} \ln \left(\frac{1+r}{1-r}\right) .
$$

The probability $p$ that the two correlations are related can be calculated with the confidence interval around the Fisher's $z$ [80]. The smaller $p$ the higher is the probability that the two correlations are not related. This means if $p<0.05$ the difference is significant if $p<0.01$ the difference is very significant and if $p<0.001$ the difference is highly significant.

\section{Appendix A.3. Standardization}

The standardization is used to find the values that differ most from the average. The standardized form $z$ of a variable $x$ is calculated as

$$
z(x)=\frac{x-\mu}{\sigma}
$$

with the mean $\mu$ and the standard deviation $\sigma$. The higher the absolute value of $z$ the more extreme is the variable $x$.

\section{References}

1. Schnelle, F. Pflanzen-Phänologie; Akademische Verlagsgesellschaft Geest \& Portig: Leipzig, Germany, 1955.

2. Walther, G.; Post, E.; Convey, P.; Menzel, A.; Parmesan, C.; Beebee, T.; Fromentin, J.; Hoegh-Guldberg, O.; Bairlein, F. Ecological responses to recent climate change. Nature 2002, 416, 389-395. [CrossRef]

3. Parmesan, C. Ecological and evolutionary responses to recent climate change. Annu. Rev. Ecol. Evol. Syst. 2006, 37, 637-669. [CrossRef]

4. Parmesan, C.; Yohe, G. A globally coherent fingerprint of climate change impacts across natural systems. Nature 2003, 421, 37-42. [CrossRef] 
5. Settele, J.; Scholes, R.; Betts, R.; Bunn, S.; Leadley, P.; Nepstad, D.; Overpeck, J.; Taboad, M. Terrestrial and inland water systems. In Climate Change 2014: Impacts, Adaptation, and Vulnerability. Part A: Global and Sectoral Aspects. Contribution of Working Group II to the Fifth Assessment Report of the Intergovernmental Panel on Climate Change; Cambridge University Press: Cambridge, UK; New York, NY, USA, 2014; pp. 271-359.

6. Menzel, A.; Fabian, P. Growing season extended in Europe. Nature 1999, 397, 659. [CrossRef]

7. Jeong, S.J.; HO, C.H.; GIM, H.J.; Brown, M.E. Phenology shifts at start vs. end of growing season in temperate vegetation over the Northern Hemisphere for the period 1982-2008. Glob. Chang. Biol. 2011, 17, $2385-2399$. [CrossRef]

8. Reyes-Fox, M.; Steltzer, H.; Trlica, M.; McMaster, G.S.; Andales, A.A.; LeCain, D.R.; Morgan, J.A. Elevated $\mathrm{CO}_{2}$ further lengthens growing season under warming conditions. Nature 2014, 510, $259-262$. [CrossRef] [PubMed]

9. White, M.; Thornton, P.; Running, S. A continental phenology model for monitoring vegetation responses to interannual climatic variability. Glob. Biogeochem. Cycles 1997, 11, 217-234. [CrossRef]

10. Heide, O.M. Growth and dormancy in Norway spruce ecotypes (Picea abies) I. Interaction of photoperiod and temperature. Physiol. Plant. 1974, 30,1-12. [CrossRef]

11. Oleksyn, J.; Tjoelker, M.; Reich, P.B. Growth and biomass partitioning of populations of European Pinus sylvestris L. under simulated $50^{\circ}$ and $60^{\circ} \mathrm{N}$ daylengths: Evidence for photoperiodic ecotypes. New Phytol. 1992, 120, 561-574. [CrossRef]

12. Hodges, T. Temperature and water stress effects on phenology. In Predicting Crop Phenology; CRC Press: Boca Raton, FL, USA, 1991; pp. 7-13.

13. Shen, M.; Tang, Y.; Chen, J.; Zhu, X.; Zheng, Y. Influences of temperature and precipitation before the growing season on spring phenology in grasslands of the central and eastern Qinghai-Tibetan Plateau. Agric. For. Meteorol. 2011, 151, 1711-1722. [CrossRef]

14. Chmielewski, F.M.; Rötzer, T. Annual and spatial variability of the beginning of growing season in Europe in relation to air temperature changes. Clim. Res. 2002, 19, 257-264. [CrossRef]

15. Watson, D.J. Comparative physiological studies on the growth of field crops: I. Variation in net assimilation rate and leaf area between species and varieties, and within and between years. Ann. Bot. 1947, 11, 41-76. [CrossRef]

16. Currie, P.O.; Peterson, G. Using growing-season precipitation to predict crested wheatgrass yields. J. Range Manag. 1966, 19, 284-288. [CrossRef]

17. Gilgen, A.K.; Buchmann, N. Response of temperate grasslands at different altitudes to simulated summer drought differed but scaled with annual precipitation. Biogeosci. Discuss. 2009, 6, 5217-5250. [CrossRef]

18. Peñuelas, J.; Rutishauser, T.; Filella, I. Phenology Feedbacks on Climate Change. Science 2009, 324, 887-888. [CrossRef] [PubMed]

19. Collatz, G.J.; Bounoua, L.; Los, S.; Randall, D.; Fung, I.; Sellers, P. A mechanism for the influence of vegetation on the response of the diurnal temperature range to changing climate. Geophys. Res. Lett. 2000, 27, 3381-3384. [CrossRef]

20. Tölle, M.H.; Gutjahr, O.; Busch, G.; Thiele, J.C. Increasing bioenergy production on arable land: Does the regional and local climate respond? Germany as a case study. J. Geophys. Res. Atmos. 2014, 119, $2711-2724$. [CrossRef]

21. Stéfanon, M.; Drobinski, P.; d'Andrea, F.; de Noblet-Ducoudré, N. Effects of interactive vegetation phenology on the 2003 summer heat waves. J. Geophys. Res. Atmos. 2012, 117, D24103. [CrossRef]

22. Yang, Z.L.; Dai, Y.; Dickinson, R.E.; Shuttleworth, W.J. Sensitivity of ground heat flux to vegetation cover fraction and leaf area index. J. Geophys. Res. Atmos. 1999, 104, 19505-19514. [CrossRef]

23. Williams, I.N.; Torn, M.S. Vegetation controls on surface heat flux partitioning, and land-atmosphere coupling. Geophys. Res. Lett. 2015, 42, 9416-9424. [CrossRef]

24. Richardson, A.D.; Keenan, T.F.; Migliavacca, M.; Ryu, Y.; Sonnentag, O.; Toomey, M. Climate change, phenology, and phenological control of vegetation feedbacks to the climate system. Agric. For. Meteorol. 2013, 169, 156-173. [CrossRef]

25. Oleson, K.; Lawrence, D.; Bonan, G.; Drewniak, B.; Huang, M.; Koven, C.; Levis, S.; Li, F.; Riley, W.; Subin, Z; et al. Technical description of version 4.5 of the Community Land Model (CLM). 2013. Available online: http:/ / www.cesm.ucar.edu/ (accessed on 6 November 2019). 
26. Sitch, S.; Smith, B.; Prentice, I.; Arneth, A.; Bondeau, A.; Cramer, W.; Kaplan, J.; Levis, S.; Lucht, W.; Sykes, M.; et al. Evaluation of ecosystem dynamics, plant geography and terrestrial carbon cycling in the LPJ dynamic global vegetation model. Glob. Chang. Biol. 2003, 9, 161-185. [CrossRef]

27. Ryder, J.; Polcher, J.; Peylin, P.; Ottle, C.; Chen, Y.Y.; van Gorsel, E.; Haverd, V.; McGrath, M.; Naudts, K.; El Zohbi, J.; et al. A multi-layer land surface energy budget model for implicit coupling with global atmospheric simulations. Geosci. Model Dev. Discuss. 2014, 7, 8649-8701. [CrossRef]

28. National Research Council. Strategies for Developing Climate Models: Model Hierarchy, Resolution, and Complexity. In A National Strategy for Advancing Climate Modeling; The National Academies Press: Washington, DC, USA, 2012. [CrossRef]

29. Doms, G.; Förstner, J.; Heise, E.; Herzog, H.J.; Mironov, D.; Raschendorfer, M.; Reinhardt, T.; Ritter, B.; Schrodin, R.; Schulz, J.-P.; et al. A Description of the Nonhydrostatic Regional COSMO Model. Part II: Physical Parameterization; Deutscher Wetterdienst: Offenbach, Germany, 2011; 154p.

30. Schulz, J.-P.; Vogel, G.; Becker, C.; Kothe, S.; Rummel, U.; Ahrens, B. Evaluation of the ground heat flux simulated by a multi-layer land surface scheme using high-quality observations at grass land and bare soil. Meteorol. Z. 2016, 25, 607-620. [CrossRef]

31. Schulz, J.-P.; Vogel, G. Improving the Processes in the Land Surface Scheme TERRA: Bare Soil Evaporation and Skin Temperature. Atmosphere 2020, 11, 513. [CrossRef]

32. Dickinson, R.E. Modeling evapotranspiration for three-dimensional global climate models. Clim. Process. Clim. Sensit. 1984, 29, 58-72.

33. Schättler, U.; Blahak, U. A Description of the Nonhydrostatic Regional COSMO-Model. Part V: Preprocessing: Initial and Boundary Data for the COSMO-Model; Deutscher Wetterdienst: Offenbach, Germany, 2017; pp. 16-25.

34. Murray-Tortarolo, G.; Anav, A.; Friedlingstein, P.; Sitch, S.; Piao, S.; Zhu, Z.; Poulter, B.; Zaehle, S.; Ahlström, A.; Lomas, M.; et al. Evaluation of land surface models in reproducing satellite-derived LAI over the high-latitude Northern Hemisphere. Part I: Uncoupled DGVMs. Remote Sens. 2013, 5, 4819-4838. [CrossRef]

35. Knorr, W.; Kaminski, T.; Scholze, M.; Gobron, N.; Pinty, B.; Giering, R.; Mathieu, P.P. Carbon cycle data assimilation with a generic phenology model. J. Geophys. Res. Biogeosci. 2010, 115, G04017. [CrossRef]

36. Neisser, J.; Adam, W.; Beyrich, F.; Leiterer, U.; Steinhagen, H. Atmospheric boundary layer monitoring at the Meteorological Observatory Lindenberg as a part of the "Lindenberg Column": Facilities and selected results. Meteorol. Z. 2002, 11, 241-253. [CrossRef]

37. Beyrich, F.; Adam, W.K. Site and Data Report for the Lindenberg Reference Site in CEOP-Phase I. In Berichte des Deutschen Wetterdienstes 230; Selbstverlag des Deutschen Wetterdienstes: Leipzig, Germany, 2007; pp. 17-42.

38. Jäger, H.; Schmidt, S.; Kammann, C.; Grünhage, L.; Müller, C.; Hanewald, K. The University of Giessen Free-Air Carbon Dioxide Enrichment study: Description of the experimental site and of a new enrichment system. J. Appl. Bot. 2003, 77, 117-127.

39. Andresen, L.C.; Yuan, N.; Seibert, R.; Moser, G.; Kammann, C.I.; Luterbacher, J.; Erbs, M.; Müller, C. Biomass responses in a temperate European grassland through 17 years of elevated $\mathrm{CO}_{2}$. Glob. Chang. Biol. 2018, 24, 3875-3885. [CrossRef] [PubMed]

40. Post, H.; Hendricks Franssen, H.J.; Han, X.; Baatz, R.; Montzka, C.; Schmidt, M.; Vereecken, H. Evaluation and uncertainty analysis of regional-scale CLM4. 5 net carbon flux estimates. Biogeosciences 2018, 15, 187-208. [CrossRef]

41. Bogena, H.; Montzka, C.; Huisman, J.; Graf, A.; Schmidt, M.; Stockinger, M.; von Hebel, C.; Hendricks-Franssen, H.; van der Kruk, J.; Tappe, W.; et al. The TERENO-Rur Hydrological Observatory: A multiscale multi-compartment research platform for the advancement of hydrological science. Vadose Zone J. 2018, 17, 1-22. [CrossRef]

42. Merkel, A.O.P.A. Climate-Data.org. Available online: https://de.climate-data.org/europa/deutschland/ (accessed on 13 February 2020).

43. Rauthe, M.; Steiner, H.; Riediger, U.; Mazurkiewicz, A.; Gratzki, A. A Central European precipitation climatology-Part I: Generation and validation of a high-resolution gridded daily data set (HYRAS). Meteorol. Z. 2013, 22, 235-256. [CrossRef] 
44. Kundzewicz, Z.W.; Radziejewski, M.; Pinskwar, I. Precipitation extremes in the changing climate of Europe. Clim. Res. 2006, 31, 51-58. [CrossRef]

45. Bartholy, J.; Pongrácz, R. Regional analysis of extreme temperature and precipitation indices for the Carpathian Basin from 1946 to 2001. Glob. Planet. Chang. 2007, 57, 83-95. [CrossRef]

46. Yan, Z.; Jones, P.; Davies, T.; Moberg, A.; Bergstrom, H.; Camuffo, D.; Cocheo, C.; Maugeri, M.; Demarée, G.; Verhoeve, T.; et al. Trends of extreme temperatures in Europe and China based on daily observations. Clim. Chang. 2002, 53, 355-392. [CrossRef]

47. González-Aparicio, I.; Hidalgo, J. Dynamically based future daily and seasonal temperature scenarios analysis for the northern Iberian Peninsula. Int. J. Climatol. 2012, 32, 1825-1833. [CrossRef]

48. Cutini, A.; Matteucci, G.; Mugnozza, G.S. Estimation of leaf area index with the Li-Cor LAI 2000 in deciduous forests. For. Ecol. Manag. 1998, 105, 55-65. [CrossRef]

49. Li-Cor, I. LAI-2000 Plant Canopy Analyzer Instruction Manual; LI-COR Inc.: Lincoln, NE, USA, 1992.

50. Kammann, C.; Grunhage, L.; Gruters, U.; Janze, S.; Jager, H. Response of aboveground grassland biomass and soil moisture to moderate long-term CO2 enrichment. Basic Appl. Ecol. 2005, 6, 351-365. [CrossRef]

51. Smets, B.; Verger, A.; Camacho, F.; Van der Goten, R.; Jacobs, T. Copernicus Global Land Operations "Vegetation and Energy", PRODUCT USER MANUAL. Issue 1.33-Version 2. 2019. Available online: https:/ / land.copernicus.eu/ (accessed on 21 November 2019).

52. Verger, A.; Baret, F.; Weiss, M. Near real-time vegetation monitoring at global scale. IEEE J. Sel. Top. Appl. Earth Obs. Remote Sens. 2014, 7, 3473-3481. [CrossRef]

53. Chen, J.; Menges, C.; Leblanc, S. Global mapping of foliage clumping index using multi-angular satellite data. Remote Sens. Environ. 2005, 97, 447-457. [CrossRef]

54. Baret, F.; Weiss, M.; Lacaze, R.; Camacho, F.; Makhmara, H.; Pacholcyzk, P.; Smets, B. GEOV1: LAI and FAPAR essential climate variables and FCOVER global time series capitalizing over existing products. Part1: Principles of development and production. Remote Sens. Environ. 2013, 137, 299-309. [CrossRef]

55. Camacho, F.; Cernicharo, J.; Lacaze, R.; Baret, F.; Weiss, M. GEOV1: LAI, FAPAR essential climate variables and FCOVER global time series capitalizing over existing products. Part 2: Validation and intercomparison with reference products. Remote Sens. Environ. 2013, 137, 310-329. [CrossRef]

56. Rockel, B.; Will, A.; Hense, A. The regional climate model COSMO-CLM (CCLM). Meteorol. Z. 2008, 17, 347-348. [CrossRef]

57. Baldauf, M.; Seifert, A.; Förstner, J.; Majewski, D.; Raschendorfer, M.; Reinhardt, T. Operational convective-scale numerical weather prediction with the COSMO model: Description and sensitivities. Mon. Weather. Rev. 2011, 139, 3887-3905. [CrossRef]

58. Dee, D.P.; Uppala, S.M.; Simmons, A.J.; Berrisford, P.; Poli, P.; Kobayashi, S.; Andrae, U.; Balmaseda, M.A.; Balsamo, G.; Bauer, P.; et al. The ERA-Interim reanalysis: Configuration and performance of the data assimilation system. Q. J. R. Meteorol. Soc. 2011, 137, 553-597. [CrossRef]

59. Jameson, A.; Schmidt, W.; Turkel, E. Numerical solution of the Euler equations by finite volume methods using Runge Kutta time stepping schemes. In Fluid Mechanics and Heat Transfer; NASA Center for Aerospace Information (CASI): Hanover, MD, USA, 1981.

60. Tiedtke, M. Parameterization of cumulus convection in large-scale models. In Physically-Based Modelling and Simulation of Climate and Climatic Change; Springer: Berlin/Heidelberg, Germany, 1988; pp. 375-431.

61. Jarvis, P. The interpretation of the variations in leaf water potential and stomatal conductance found in canopies in the field. Philos. Trans. R. Soc. London. Biol. Sci. 1976, 273, 593-610.

62. Smiatek, G.; Rockel, B.; Schättler, U. Time invariant data preprocessor for the climate version of the COSMO model (COSMO-CLM). Meteorol. Z. 2008, 17, 395-405. [CrossRef]

63. Smith, B.; Prentice, I.C.; Sykes, M.T. Representation of vegetation dynamics in the modelling of terrestrial ecosystems: Comparing two contrasting approaches within European climate space. Glob. Ecol. Biogeogr. 2001, 10, 621-637. [CrossRef]

64. Raddatz, T.; Reick, C.; Knorr, W.; Kattge, J.; Roeckner, E.; Schnur, R.; Schnitzler, K.G.; Wetzel, P.; Jungclaus, J. Will the tropical land biosphere dominate the climate-carbon cycle feedback during the twenty-first century? Clim. Dyn. 2007, 29, 565-574. [CrossRef]

65. Reick, C.; Raddatz, T.; Brovkin, V.; Gayler, V. Representation of natural and anthropogenic land cover change in MPI-ESM. J. Adv. Model. Earth Syst. 2013, 5, 459-482. [CrossRef] 
66. Giorgetta, M.A.; Jungclaus, J.; Reick, C.H.; Legutke, S.; Bader, J.; Böttinger, M.; Brovkin, V.; Crueger, T.; Esch, M.; Fieg, K.; et al. Climate and carbon cycle changes from 1850 to 2100 in MPI-ESM simulations for the Coupled Model Intercomparison Project phase 5. J. Adv. Model. Earth Syst. 2013, 5, 572-597. [CrossRef]

67. Jacob, D.; Podzun, R. Sensitivity studies with the regional climate model REMO. Meteorol. Atmos. Phys. 1997, 63, 119-129. [CrossRef]

68. Wilhelm, C.; Rechid, D.; Jacob, D. Dynamic coupling of regional atmosphere to biosphere in the new generation regional climate system model REMO-iMOVE. Geosci. Model Dev. Discuss. 2013, 6, 3085-3135. [CrossRef]

69. Schulz, J.-P.; Vogel, G.; Ahrens, B. A new leaf phenology for the land surface scheme TERRA of the COSMO atmospheric model. COSMO Newsl. 2015, 15. Available online: http:/ / www.cosmo-model.org/ (accessed on 5 March 2019).

70. Piao, S.; Tan, J.; Chen, A.; Fu, Y.; Ciais, P.; Liu, Q.; Janssens, I.; Vicca, S.; Zeng, Z.; Jeong, S.J.; et al. Leaf onset in the northern hemisphere triggered by daytime temperature. Nat. Commun. 2015, 6, 6911. [CrossRef]

71. Gardner, W.; Ehlig, C. The influence of soil water on transpiration by plants. J. Geophys. Res. 1963, 68, 5719-5724. [CrossRef]

72. Woodward, F.I. Climate and Plant Distribution; Cambridge University Press: Cambridge, UK, 1987.

73. Anav, A.; Murray-Tortarolo, G.; Friedlingstein, P.; Sitch, S.; Piao, S.; Zhu, Z. Evaluation of land surface models in reproducing satellite Derived leaf area index over the high-latitude northern hemisphere. Part II: Earth system models. Remote Sens. 2013, 5, 3637-3661. [CrossRef]

74. Umweltbundesamt. Umwelt und Landwirtschaft. 2018. Available online: https://www.umweltbundesamt. de/sites/default/files/medien/421/publikationen/20180125_uba_fl_umwelt_und_landwirtschaft_bf_ final.pdf (accessed on 13 October 2020).

75. Davin, E.L.; Seneviratne, S.I.; Ciais, P.; Olioso, A.; Wang, T. Preferential cooling of hot extremes from cropland albedo management. Proc. Natl. Acad. Sci. USA 2014, 111, 9757-9761. [CrossRef]

76. Reichstein, M.; Ciais, P.; Papale, D.; Valentini, R.; Running, S.; Viovy, N.; Cramer, W.; Granier, A.; Ogée, J.; Allard, V.; et al. Reduction of ecosystem productivity and respiration during the European summer 2003 climate anomaly: A joint flux tower, remote sensing and modelling analysis. Glob. Chang. Biol. 2007, 13, 634-651. [CrossRef]

77. Luterbacher, J.; Liniger, M.A.; Menzel, A.; Estrella, N.; Della-Marta, P.M.; Pfister, C.; Rutishauser, T.; Xoplaki, E. Exceptional European warmth of autumn 2006 and winter 2007: Historical context, the underlying dynamics, and its phenological impacts. Geophys. Res. Lett. 2007, 34, L12704. [CrossRef]

78. Pearson, K.; Filon, L.N.G. VII. Mathematical contributions to the theory of evolution.-IV. On the probable errors of frequency constants and on the influence of random selection on variation and correlation. Philos. Trans. R. Soc. London. Series Contain. Pap. Math. Phys. Character 1898, 229-311.

79. Fisher, R.A. Statistical Methods for Research Workers; Oliver and Boyd: Edinburgh, UK, 1925; Volume 6.

80. Eid, M.; Gollwitzer, M.; Schmitt, M. Statistik und Forschungsmethoden: Mit Online-Materialien; Weinheim: Basel, Beltz, 2017; Volume 5.

Publisher's Note: MDPI stays neutral with regard to jurisdictional claims in published maps and institutional affiliations.

(C) 2020 by the authors. Licensee MDPI, Basel, Switzerland. This article is an open access article distributed under the terms and conditions of the Creative Commons Attribution (CC BY) license (http://creativecommons.org/licenses/by/4.0/). 